\title{
Perforation mode of Second-class- Reservoir series adhesive layer YANG GUIXIA
}

\author{
(No.3.Oil Production Plant of Daqing Oilfield Company Ltd,Daqing ,Heilongjiang , China \\ 163113,zxt770720@126.com)
}

Key words: Second-Class-Reservoir; adhesive layer; perforation mode

\begin{abstract}
Completion of polymer flooding wells in Second-Class-Reservoir, 46 wells ( $11.1 \%$ ) with interval less than $1 \mathrm{~m}$ or partial small layers are fully bonded according to logging curves. in principle, some or all of these layers shall be deducted as interval layers before perforation to ensure the development needs. In order to improve the control degree of polymer flooding well and fully excavate the remaining oil, the treatment methods of these adhesive layers are put forward in this paper.
\end{abstract}

\section{Foreword}

Second-Class- Reservoir polymer flooding, using $125 \times 125 \mathrm{~m}$ five-point method area of well pattern, all except fault area of new wells, a total of 1106 wells.

After completion of new well, the sand body distribution, shape change, oil layer development and residual oil distribution are re - recognized. based on the relatively mature perforation program compiling experience, the existing problems such as formation adhesion between the adjustment target interval and the non-adjustment interval, isolated sand body and the same well site are studied in detail, and gradually improved and improved in line with the principle of preparation and adjustment synchronization.

\section{Geological characteristics of two type reservoir}

Second-Class- Reservoir oir polymer flooding wells are divided into A and B series from top to bottom, A series as the upper return series, B series as the current production series, adjust the length of the well section $46 \mathrm{~m}$, the average adjustable sandstone thickness of $13.4 \mathrm{~m}$, effective $10.8 \mathrm{~m}$.. There are 18 sedimentary units in the vertical direction and 2 kinds of 4 sedimentary types in the plane, mainly the front-edge facies of the delta and the branch-lump transitional delta. Compared with each unit reservoir, although the sand body types are generally the same, there are big differences in the size and thickness of the river sand body.

Table 1 The statistics of well number to be Second-Class-Reservoir adhesive layer

\begin{tabular}{|c|c|c|c|c|}
\hline Numberof sedimentary unit layer & Based on A & Based on B & Half of each & Total \\
\hline $7-11$ & & 2 & 6 & 8 \\
\hline $7-12$ & & & 1 & 1 \\
\hline $9-11$ & 4 & 9 & 2 & 6 \\
\hline $9-12$ & 1 & 3 & 2 & 3 \\
\hline $9-14$ & & 1 & 26 & 46 \\
\hline Total & 5 & 15 & & 28 \\
\hline
\end{tabular}

The first unit of B - series is the front edge sand body of the branch -lump transitional delta, two branch river sand bodies are developed, and large-area pointed-out areas are developed at the same time. The lowermost unit of layer a is the sand body of the front edge of the branch delta, and the sand body of the branch network channel is developed. Due to the influence of the sedimentary environment of the oil layer, the oil layers between the two sets of strata A and B overlap and cut down, resulting in large area adhesion, only the number of sticking wells in this strip reaches 24 . The reservoir adhesion between the $\mathrm{A}$ and $\mathrm{B}$ adjustment formations is severe.

According to statistics, there are 415 wells with the lithologic interval less than $2.0 \mathrm{~m}$ between the 
adjustment interval and the non-adjustment interval, accounting for $33.49 \%$. after deducting the thin layer and the physical interval less than $2.0 \mathrm{~m}$, there are 79 new wells with 53 wells with the physical interval less than $1.0 \mathrm{~m}$, of which 46 wells are fully bonded, and 13 wells are independent reservoirs. But the two unit layer are well developed, perfect injection production relationship formed in each unit, because of the blocking conditions can not meet the two small compartment on the back of the reservoir, deduct part of which unit will cause loss of reserves or injection production relationship is not perfect, increase plan and adjust the difficulty.

Table 2 The statistics of well number to be property interlayer less than $2.0 \mathrm{~m}$

\begin{tabular}{|c|c|c|c|c|}
\hline Interlayer & Based on A & Based on B & Half of each & Total \\
\hline$\geqslant 1.5 \mathrm{~m}$ & 2 & & 5 & 7 \\
\hline $1.0 \sim 1.4 \mathrm{~m}$ & & 2 & 2 & 4 \\
\hline$<1.0 \mathrm{~m}$ & & & 2 & 2 \\
\hline Total & 2 & 2 & 9 & 13 \\
\hline
\end{tabular}

The principle of layer combination

According to the above research results, the principle of the combination of the three oil layers in the Saertu oil layer is determined as follows:

The thickness of a set of layers depends on the scale of the system and the replacement of the production and the total thickness of the overall back layer. The thickness of the layer system should be as uniform as possible and the minimum thickness is $6 \mathrm{~m}$.

The three oil recovery units in one set of strata should be relatively concentrated, and the geological conditions in the strata should be as close as possible.

The formation of the sandstone group is composed of layers. There is a more stable layer between three oil recovery layers, and the drilling rate of a well with a thickness of more than $1.5 \mathrm{~m}$ should be more than $80 \%$.

The three oil recovery adjustment objects are mainly channel sand and non channel sand with effective thickness greater than $1 \mathrm{~m}$, and the effective permeability is more than $0.1 \mathrm{Mu} \mathrm{m} 2$.

\section{Principle and method of treatment of laminated adhesive layer}

The big problem brought by the adhesive layer of the layer system is that the layer system is not closely divided, and the plugging difficulty is large when the layer system returns upwards. The upward or downward spread affects the adjusted thickness to the current production interval or the second upward return interval. If the adhesive layer is perforated together during the mining, on the one hand, the adjustable thickness of the secondary upper return well section is reduced; If the adhesive layer is perforated together when it is returned twice, it is difficult to guarantee the thickness of the perforation at present.

\subsection{Principle of treatment of laminated adhesive layer}

Considering the Second-Class- Reservoir flooding is to improve the control degree of flooding, fully mining residual oil as the main purpose, not only to ensure that each adjustment well section has a certain perforation thickness, but also to ensure that the adjustment layer system as complete and unified as possible. To this end, the overall treatment principle of the laminated adhesive layer is formulated:

According to the principle of maximizing the reserve potential, all oil layers meeting perforation conditions should be shot as far as possible;

For the first time to adjust the hierarchy is not disorderly;

Take the injection well as the center, the oil recovery well improves the injection production relationship according to the injection well shooting.

Ensure stable interlayer.

\subsection{Processing method}

Combined with the above treatment principles, the proportion of the adhesive layer in each unit and the 
distribution of the interlayer in the longitudinal direction, the adhesive oil layer is divided into the following categories, according to different types of different treatment methods:

3.2.1. The oil layer mainly composed of layer $\mathrm{A}$ is not perforated below the adjustment layer system node at present, and is not perforated when returning upward, and is used as the interlayer of the layer system.

The reservoir above the node is well developed, mainly with river sand and perfect injection-production relationship on the plane, which is the main potential digging object when returning twice. The reservoir development of the unit below the node is relatively poor, mainly thin sand or Table-out layer, and the injection-production relationship is relatively imperfect. For such a well group, at present, the unit oil layer below the adjustment system node is not perforated, and this part is not perforated at the time of secondary upward return, as the system interlayer.Such as injection well J1 well group, the cohesive layer sandstone $3.2 \mathrm{~m}$, effective $2.6 \mathrm{~m}$, including more than node a part of sandstone $2.6 \mathrm{~m}$, effective $2.0 \mathrm{~m}, 3$ of the 4 production wells is located in the river sand, the other is also effective thickness of $1.0 \mathrm{~m}$, the well group of reservoir development, injection-production relationship is perfect, is the main potential object when the second return; Under the node $b$ part of sandstone $0.6 \mathrm{~m}$, effective $0.6 \mathrm{~m}$, there are 3 production wells oil layer difference can not perforation, so part B not perforation as a series of interlayer, the second return when this part does not fill hole.

3.2.2 The oil layer mainly composed of B series is currently perforated below the adjustment series node and blocked when returning upward.

The reservoir development of the unit above the node is relatively poor, mainly non-principal de sable or off-balance-sheet layer, the injection-production relationship is not perfect on the plane, and the reservoir development of the unit below the node is better, mainly river sand or main river sand, and the injection-production relationship is perfect. For such a well group, partial perforation of section B is currently adjusted, whereas partial perforation of section A is not used as a series spacer. Such as injection well $\mathrm{J} 2$ well group, single layer sandstone above the node $0.9 \mathrm{~m}$, effective $0.6 \mathrm{~m}$, permeability of $0.380 \mu \mathrm{m} 2$, in line with the injection well perforation conditions, and the corresponding two production wells relatively poor development of oil layer, when the second return cannot perforation; The reservoir below the node is well developed, the sandstone thickness is $3.3 \mathrm{~m}$, the effective thickness is $2.8 \mathrm{~m}$, and the injection-production relationship is perfect. therefore, at present, the perforation of the reservoir below the node below the layer system is adjusted, and the reservoir is blocked during upward return, while the part A above the node is deducted as the layer system interlayer, and no hole is added during secondary upward return.

3.2.3. The upper and lower units of the node are all good reservoirs. at present, the perforation of part B of the formation system is adjusted, and no blockage is generated when returning upward, and secondary polymer flooding exploitation is implemented.

Reservoir development of upper and lower units of the node is good, mainly river sand or the main river sand with effective thickness greater than $1.0 \mathrm{~m}$, belongs to the second type of reservoir adjustment object in each unit, has a perfect injection-production relationship, deduct which part of the reservoir will cause reserves loss and injection-production is not perfect. On the premise of ensuring the integrity and unity of the adjustment layer system, first shoot the part B oil layer below the node, and the part a oil layer above the node is not perforated at present, when the second return to part a oil layer for hole filling, the original perforation parts are not blocked, with part a to implement secondary flooding mining.

According to the development of the interlayer, under the condition of not affecting the injection-production relationship, using the method of one or two kinds of interlayer in the layer, deduct part of the oil layer, etc., as far as possible to control the sealing interlayer in the minimum range of change. The plugging horizon is determined according to the injection well conditions, and the plugging horizon of the production well is determined according to the injection well system plugging.

3.2.4. Selective perforation of oil reservoirs with isolated or incomplete well point sticking.

The cohesive oil layer is formed by isolated sand body or imperfect injection and production in a unit layer, and the oil layer is selectively perforated. If well $\mathrm{J} 3$ develops into a small lump sand body in the unit above the node, there is no injection in the secondary return, all three injection wells are pointed out, 
only $0.3 \mathrm{~m}$ thin layer is developed in one injection well, and the adjustment object of non-class ii reservoir is not found. Considering that the plugging horizon extends to the following too deep during upward return, and the injection and production of the above-node unit is not perfect, so at present, part B below the node is perforated, and part A can not be perforated during upward return, and this part of reserves can be adjusted by excavation of adjacent water flooding secondary encrypted production well $\mathrm{j} 4$. Well $\mathrm{j} 5$ is located near the fault and only two injection wells are correspondingly connected. River sand bodies can be developed in the units above the nodes, one injection and one production can be formed, river sand bodies are developed in the units below the nodes, two injection wells are poor in development, no injection wells is formed, and the well is located in the vicinity of the old injection wells, and the oil layer is well communicated with the old injection wells, high water flooding is formed at the bottom, and the water saturation reaches $73.9 \%$; in order to control the initial water cut, the units below the nodes are not perforated at present, and the unit is returned at this time.

3.2.5 The adhesive oil layer between the non-adjusted well section and the adjusted is absolutely not perrorated

The non-perforation method is adopted for the non-dajusted well section of the individual well point and the adhesive oil layer between the adjusting well section.Near the demarcation point of the oil layer in the well section, one and two types of interlayers in the inner oil layer are used as layers,and only a part of the oil layer isopended.

\section{Conclusion}

Through the above measures, the perforation interval and pre-sealing horizon of the layer-by-layer bonded oil layer can be determined layer by layer by well, which can not only cause reserves loss, but also improve the injection-production relationship. It not only ensures that the existing mining system is simple and complete, but also increases the adjusting thickness of the upper return layer system to a certain extent. This method provides convenience for development and adjustment of polymer flooding in Second-Classs-Reservoir and is successful.

\section{References:}

[1] Dou zhilin, Study on reservoir flow unit Petroleum Industry Press,2001

[2] Sui jun, Lu Xiaoguang, Zhao hanqing, Xu yunxin. Study on River delta facies reservoir in Daqing Oilfield Petroleum Industry Press,2000 